\title{
La Comunicación como Mediación Ética del mundo ante la descentralización de la persona en la acción comunicativa
}

\author{
Jorge Alberto Hidalgo Toledo* \\ José Antonio Forzán Gómez ** \\ Universidad AnÁhuac México Norte
}

La comunicación, no es un mero accidente que ocurre entre los hombres; por ello, hoy día, se distingue de informar y difundir. Comunicar, por el contrario, es dotar de significado las cosas del mundo; lo que significa, dotar de sentido a la existencia misma. El objeto del presente, una aproximación ética de la acción comunicativa considerando aquellos aspectos que dejan de manifiesto la descentralización de la persona en la acción comunicativa para registrar la propia existencia y sus condiciones éticas para hablar nuevamente de significación y sentido en la acción humana; para entender nuevamente la comunicación como la mediación ética del mundo. Así se hace una revisión de los medios como servicio a la persona, la naturaleza ética de los medios; ofreciendo dos propuestas de ética aplicada: la semioética y la infoética.

Palabras clave: ética de la comunicación, corresponsabilidad, infoética, semioética, personalismo.

* Titular de la Cátedra FISAC-Anáhuac en Comunicación para promover la Responsabilidad y la Sana Convivencia, Investigador Titular del Centro de Investigación para la Comunicación Aplicada (CICA), Maestro en Humanidades. Correo electrónico: jhidalgo@anahuac.mx; http:// inmersioneducativa.blogspot.com.

** Coordinador de Ciencias del Lenguaje, Escuela de Comunicación, Universidad Anáhuac. Investigador adscrito al Centro de Investigación para la Comunicación Aplicada. Vicepresidente de la Asociación Mexicana de Estudios de Semiótica Visual y del Espacio. Miembro de la red de investigadores de la UNAM-FEs Acatlán. Doctor en Literatura, Maestro en Semiótica y Licenciado en Comunicación. Correo electrónico: jforzan@anahuac.mx; jaforzan@gmail.com. http://espiralediciones.blogspot.com. 
The communication, is not a mere accident that happens between the men; for that reason, nowadays, it is distinguished to inform and to spread. To communicate, on the contrary, is to equip with meaning the things of the world; what means, to equip with sense the same existence. The object of the present text is an ethical approach of the communicative action considering those aspects that let of manifest the decentralization of the person in the communicative action to register the own existence and its ethical conditions to again speak of meaning and sense in the human action; in order to again understand the communication like the ethical mediation of the world. We present a revision of the media as a service to the person, the ethical nature of media; offering two proposals of applied ethics: the semioética and the infoética

Key words: Communication, corresponsability, infoethics, semioethics, media ethics.

\section{INTRODUCCIÓN}

\section{La ontología de la comunicación}

Es la comunicación un acto referencial dotado de sentido y significación. Y decimos referencial porque es a través del lenguaje y su carácter comunitario que invocamos, evocamos y se nos "autorrevela el mundo" (Cassirer, 1985, p. 18). Esta interacción sintáctica y dinámica entre la materia, el individuo, la percepción, la memoria, los sentidos y la inteligencia es la que permite unirnos semánticamente a los demás seres morales y compartir con ellos valores, tradiciones, costumbres e ideas enriqueciendo la experiencia vital. De esta forma, la comunicación constituye, no una intención vacía como creía Husserl sino como bien apunta Sastre, "una experiencia trascendental" (Sartre, 2000, p. 307); una relación de compromiso que sobrepasa la gramática, la realidad y el lenguaje. Comunicar es "extender la mano" (López Quintás, 1968, p. 125), es encuentro, es intimidad, es vincularse con el otro, es diálogo, es entrega, es construcción comunitaria, es donación y servicio al otro y por los otros.

La comunicación, no es un mero accidente que ocurre entre los hombres; por ello, hoy día, se distingue de informar ${ }^{1}$ y difundir ${ }^{2}$. Comunicar, por el contrario,

\footnotetext{
${ }^{1}$ Entiéndase como un simple intercambio ausente de diálogo y unidireccional de datos sin más sentido que la respuesta.

${ }^{2}$ Léase como sacar de la oscuridad un hecho, mostrarlo a la luz pública a través de todos los canales posibles.
}

86• Jorge Alberto Hidalgo Toledo, José Antonio Forzán Gómez 
es dotar de significado las cosas del mundo (no un suspender al hombre fuera del acontecer como pretende el simple entretener); lo que significa, dotar de sentido a la existencia misma. Con ello se quiere apuntalar que es la persona el centro y el destino de la acción comunicativa. Lo que debería llevarnos a creer que en cada palabra vertida en un Chat, en cada imagen transmitida por televisión; o en cada video emitido bajo demanda por Youtube; en cada sonido descargado de Limewire y iPodder o sintonizado en la radio debería haber, como afirmaba Gabriel Marcel, una "certeza existencial" (Sanabria, 2000, p.155), pero parecieran no darse del todo. Esta invocación recíproca de encuentros interpersonales es la ontología misma de la comunicación. Quienes buscan el "Ser" de la comunicación, en el fondo buscan al hombre mismo. Siendo la humanidad entera la que se oculta detrás del fenómeno comunicativo es vital analizar la función de los medios y ver si estos, en verdad, están al servicio del hombre y como facilitadores de que éste descubra el sentido último de su existencia. La interacción simbólica que se ha tendido en Internet y la convergencia tecnológica, han puesto al descubierto la ausencia de un rostro y la desnudez del cuerpo. Así mismo, han dejado ver la necesidad de replantear las funciones tradicionales (informar, comunicar y difundir) y considerar la formación y configuración del hombre a través de los contenidos a los que se expone. Por ello, se plantea a lo largo del texto, la indigencia comunicativa, de egoísmo simbólico, de extranjeros gramaticales, de ausencias cognoscitivas, de despojo mediático, de soledad significativa, de pobreza informativa, de miseria existencial que se está viviendo en algunos ámbitos de la comunicación masiva por una falta de inclusión ética y antropológica en la pragmática misma de la comunicación.

Quizá el problema más grave y evidente de la comunicación en nuestros días no sea la brecha informativa, como se ha querido insistir, sino la ausencia de una metafísica significativa que permita nuevamente la posesión del mundo y la instauración de una comunidad universal de personas por el don de la comunicación. Devolver el sentido trascendente a la acción comunicativa implica volver los ojos a la centralidad de la persona, al reconocimiento y valoración del otro, a la ética y a los fundamentos de los medios: servir (buscar el bien común), unir (solidaridad) y equilibrar (justicia) a la sociedad. He aqui el objeto del presente, una aproximación ética de la acción comunicativa considerando aquellos aspectos que dejan de manifiesto la descentralización de la persona en la acción comunicativa para regresar al "ser a su morada" (Heidegger, 1987, p. 26); para registrar la propia existencia y sus condiciones éticas para hablar nuevamente

La Comunicación como Mediación Ética del mundo $\bullet 7$ ante la descentralización de la persona en la acción comunicativa 
de significación y sentido en la acción humana; para entender nuevamente la comunicación como la mediación ética del mundo 3 .

\section{LOS MEDIOS AL SERVICIO DE LA PERSONA}

\section{a. ¿Qué es persona?}

En nuestros días, definir al hombre continúa siendo una de las más grandes dificultades en los planteamientos, tanto científicos como filosóficos. Ello porque hoy, tan cercanos al proyecto de la genética y la transformación de la creación natural, la misma interrogante presocrática sigue siendo vigente. Para poder definir un marco de acción o de postulación científica, es fundamental comprender lo que cada autor o corriente de pensamiento entiende por hombre. Es decir, que el concepto que se tenga de ser humano en su totalidad, impactará en las acciones cotidianas, como lo son los planteamientos epistemológicos, los productos comunicativos o el simple comportamiento cotidiano. Sin pretender hacer una revisión exhaustiva, se pueden señalar las siguientes cualidades que han sido debatidas a lo largo de la historia en relación al hombre: Es una entidad corpórea; es un ser relacional.; es un ser racional; es un ser espiritual; es un ser de trascendencia; es un ser del lenguaje; es un ser que consigue la interioridad; es un ser histórico; es un ser que se construye; es un ser que deviene entre las condiciones existenciales y la libertad; es un ser mediático ${ }^{4}$.

Todos estos rasgos definitivos, podrían resumirse en un postulado: el ser humano es una persona humana. Es decir, es un ser que, manifestando lo más radical de sí, mostrando lo más profundo de su realidad ontológica, lo que expresa a través de sus actos es su unicidad. Además, la condición de la persona fundamental es su radical manifestación en el tiempo y en el espacio. El hombre como señala Sanabria (1987, pp. 85-86) "no es pura subjetividad, sino que, constitutivamente, está orientado hacia el mundo, más aún, hacia

\footnotetext{
${ }^{3} \mathrm{Si}$ las personas se construyen en función de los discursos interpersonales e históricos, habría que entender que existen puentes que permiten, como afirma Jesús Martín Barbero (1987), "reconstruir la cultura". De este modo, los medios deben mediar las acciones bajo un marco ético; así las acciones personales, simbólicas, interpersonales y organizacionales responderían: a una ley natural, a mantener la centralidad del hombre, a elevar su dignidad y mantener el bien común conformando una red de sentido que devuelva al hombre su humanidad.

${ }^{4} \mathrm{El}$ hombre es la única especie que requiere de medios para conquistar su propia naturaleza. Ser virtuoso implica una dominación de dichos medios y disponer correctamente de ellos para dar un sentido pleno a su existencia.
}

88 • Jorge Alberto Hidalgo Toledo, José Antonio Forzán Gómez 
$s u$ mundo. Esta orientación es un modo de ser fundamental de la existencia humana. De manera que no es primero el mundo y después yo, o viceversa, sino que simultáneamente se dan yo-mundo; yo soy mi mundo. Porque el hombre es relación."

Por ello, es fundamental atender a los principios de comportamiento de la persona ante el otro donde cada hombre se debe reconocer como persona, con naturaleza dotada de inteligencia y de libre albedrío, poseedora de derechos y deberes exudados de su propia naturaleza; derechos y deberes que se manifiestan como universales, inviolables e irrenunciables. En esta manifestación del hombre; esta radicalidad de la persona humana conlleva la idea de la comunicación. Es decir, si la persona humana es en el mundo; su condición comunitaria se da porque es con-los-otros.

Ese ser-con-los otros es posible gracias al lenguaje, a la expresión del espíritu que dota de contenido a los objetos y a la persona misma. El hombre es en sí mismo el medio por el cual se realiza en el mundo; el medio que puentea la existencia del otro en el mundo; porque en el hombre mismo se construye el medio y la mirada... la mediación misma de la realidad. Para conservar su unicidad y llegar a ser, la persona requiere contar con los medios para desarrollar la virtud (Fromm, 1986, p. 39), para colocarse ante su propia naturaleza y dominarla.

En función del objeto de estudio de este trabajo, los medios masivos de comunicación, si han sido mediados por la ética, determinarán la acción del hombre sin perder de vista que el fin es el hombre mismo. Lo que permite afirmar que los medios están al servicio de la persona y no la persona al servicio de ellos.

\section{b. Los medios de comunicación al servicio de la persona}

Hoy día, los comunicólogos, antropólogos, sociólogos y politólogos hablan de la necesidad de contar con medios de comunicación libres y responsables para la creación de sistemas democráticos donde primen la libertad de expresión y de prensa. Para ello, han creado múltiples modelos y teorías de responsabilidad social, códigos de ética, vías de autorregulación y legislación para justificar el buen actuar de los medios ante la sociedad civil. Muchos han sido los estudios dedicados a los efectos de los medios y los intentos para establecer un uso ético de los mismos. Pero, ¿se puede hablar realmente de ética mediática sin limitar los esfuerzos a generar legalismos, normativas y códigos de conducta más que intentos por visualizar a los medios como herramientas colaborativas para devolver el lugar del hombre en el mundo?

La Comunicación como Mediación Ética del mundo $\bullet 89$ ante la descentralización de la persona en la acción comunicativa 
Esta reubicación del hombre, debe partir necesariamente del entender que los medios están al servicio del hombre. Pero, ¿qué implica este servicio? Cuando se habla del "servicio" que prestan los medios de comunicación, se hace referencia a su aportación para lograr un factor de crecimiento y progreso humano, progreso de la verdad del hombre, progreso cultural, social y económico. De ahí que en términos concretos se busque que los medios de comunicación estén a la defensa de la promoción de la verdad integral. Los medios deben servir para encontrar respuestas verdaderas; para desarrollar las habilidades; para conocer, compartir y comunicar las intenciones, deseos, sentimientos, conocimientos y experiencias; para comprender, actuar con libertad y progresar; para establecer relaciones, solidarizar; para enriquecer intelectual, moral, social y espiritualmente; para promocionar los valores humanos y la vida humana; para realizar un encuentro entre hombres, culturas, ideologías, historias y signos trascendentes. Cuando los medios y las nuevas tecnologías de información, pierden este sentido de utilidad, se pierde con ello el sentido de la condición humana y se terminan agrediendo: la dignidad humana, los valores universales, la cultura, los sistemas económicos, políticos y sociales. Tal ha sido el caso de los Reality shows o aquellos Game shows en el que los hombres humillan su propia condición humana a cambio de dinero fácil, fama efímera y respeto comunitario a cambio de una ilegitimidad moral.

La comunicación que se sostiene de la experiencia común, solidaria y generosa -porque ofrece lo mejor del otro- termina construyendo el cuerpo del mundo. El rostro y la identidad que tomará se define como lengua viva; pues serán los hombres los que moldeen el mundo para mejorar su condición humana y no los medios los que moldeen sus opiniones y los aspectos fundamentales de su existencia. Cuando los medios "sirven", construyen, "unen y solidarizan"; justifican la existencia, rompen con la soledad y llevan a la plenitud de cada hombre, como lo han venido haciendo algunas radios comunitarias o redes sociales solidarias en Internet. La acción fecunda de los medios es aliviar la indiferencia, eliminar el aislamiento, desbancar el rechazo, derrotar el egoísmo, reconstruir la incomprensión, diluir "la tonalidad grisácea de la existencia" (Serrano, 1970, p. 45). La soledad del hombre mediático, es la de aquél que ha visto pisoteada su intimidad por los abusos de la imagen, los vacíos de la palabra, los silencios informativos, la mezquindad de la manipulación, la persuasión de la indecencia, la falta de responsabilidad social y una ética en los medios.

Todo esquema formal e informal de control de los medios debe trascender las leyes y reglamentos para contemplar algo más que códigos de conducta.

90 • Jorge Alberto Hidalgo Toledo, José Antonio Forzán Gómez 
Una ética integral debe contemplar todos los aspectos de la persona humana y su interrelación con el medio. Los medios como bien señalaba Xavier Zubiri deben servir para "realizar la vocación humana, ser de verdad hombres" (Zubiri, 1987, p. 259).

\section{c. La naturaleza ética de los medios}

Ahora bien, si partimos de que el problema de la comunicación es el encontrar el yo gracias al tú, la dimensión de la comunicación tendría que anclarse en el problema del lenguaje, del ethos de la acción humana y el fin de los medios. La filosofía contemporánea, a partir del giro lingüístico de Wittgestein, el giro hermenéutico de Gadamer y el giro semiológico de Roland Barthes, dejó de manifiesto que el problema filosófico de la comunicación partía del lenguaje y no del medio porque es en el ethos del signo, donde se da la significación. (Barthes, 2001)

Tal visión pone en relieve a la persona humana como algo más complejo aún que una simple visión centrada en los medios y en la masa despersonalizada como la vio en su momento Abraham Moles (Moles, 1975, p. 449)

Se subraya con esto la idea de Barthes, "no es lo mismo hablarle a alguien que decirle algo". No es lo mismo informar o difundir que aportarle sentido a la vida del otro. Por tanto, pensar en los medios debe superar la concepción técnica para atender a su noción ideológica y existencial. De ahí que los productores de contenido guarden como principal responsabilidad moral la verdad de las informaciones que habrán de difundir ya que en la esencia de ese mensaje está el sentido de la respuesta que habrán de dar los receptores en su mundo.

De esta manera, los medios dejan de ser una fuerza ciega de la naturaleza fuera del control del hombre. Es por los fines, la participación del hombre, su uso como herramientas, el grado de bondad o de maldad con que se produce la acción comunicativa que los medios deben estar mediados por la ética. Dependiendo del grado de mediación ética, se puede hablar del aumento de la empatía, la compasión, la solidaridad o el odio, narcisismo o soledad entre los hombres. Con esta consideración en mente, los medios deben hacer consciente al hombre de su dignidad; lo deben llevar a comprender los sentimientos de los

\footnotetext{
5 "Mass media son a la vez esos canales de difusión y medios de expresión que se dirigen no a un individuo o persona, sino a un 'público destinatario' definido por unas características socioeconómicas y culturales en el que cada receptor es anónimo. (...) Son también los vectores unidireccionales de un mensaje emitido por un individuo o por un grupo destinado a un público mucho más amplio."
}

La Comunicación como Mediación Ética del mundo •91 ante la descentralización de la persona en la acción comunicativa 
demás, a cultivar un sentido de responsabilidad mutua, y a crecer en libertad personal, en el respeto a la libertad de los demás y en la capacidad de diálogo. Si los medios no propician el diálogo será imposible impulsar la comunicación solidaria que requieren los pueblos hoy día para fomentar valores como el respeto y la tolerancia.

\section{LA DESCENTRALIZACIÓN DE LA PERSONA EN LA ACCIÓN COMUNICATIVA}

Para hablar de una mediación ética integral se requieren personas libres y autónomas y medios de comunicación masiva, libres, responsables y éticos. Desgraciadamente algunos medios, como algunas personas, han perdido su centro y su sentido y ante el fenómeno de la globalización tenderán a agravarse. Algunos de los problemas de esta descentralización de la persona en la acción comunicativa nacen de la errónea concepción que se tiene de la libertad, la expresión, la equidad y la justicia; así como de la falta de códigos y principios que trasciendan los límites legales o que se quedan sólo en la regulación de conductas empresariales para limpiar su imagen. Hoy se pueden encontrar tendencias en que los medios se han convertido en medios de presión o defensa de intereses por parte de la sociedad. Esta tendencia empieza a generalizarse tanto en los medios privados como en los públicos. En contraparte resuena cada vez más la existencia de medios que hacen conciencia de que tienen una responsabilidad y deben guardar una misión de servicio. Al estar mediando los intereses de la sociedad civil, los grandes poderes y, de las personas, los medios están obligados a vigilar el cumplimiento ético de las dinámicas sociales y el desarrollo comunitario.

\section{a. La libertad como base de la acción comunicativa}

Eje central de la acción comunicativa es la libertad como fundamento de la subjetividad plena que da sentido al mundo. El hombre, al inventarse a sí mismo en cada instante, realiza su esencia suspendida en la libertad, condición que permite justificar su actuar en el mundo pues lo hace "responsable de su persona" (Bennett, 2001). La persona humana que aspira al bien tiene en cuenta su lugar en el mundo, en la historia, en el tiempo. Su condición radical de ser-enel-mundo: "la libertad necesariamente es una libertad situada. La razón de esto es muy sencilla: el hombre concreto vive su aqui y su ahora." (Sanabria, 2000). Al hacer conciencia del mundo, el hombre se da cuenta de que sus decisiones, los actos que dan sentido a su vida, están, condicionados por factores que dan

92 • Jorge Alberto Hidalgo Toledo, José Antonio Forzán Gómez 
razón de ser a su persona, pero que, incluso, llegan a atentar en contra de su dignidad. De ahí la tarea de cada persona: lograr progresivamente una libertad cada vez más auténtica; mientras más libre, más persona.

Sanabria subraya así, la radical misión de la ética: "En nuestros días hay muchos obstáculos para la auténtica libertad; son los factores despersonalizantes. De ahí la obligación, o la tarea, de luchar por la realización de la libertad -el hombre vale por lo que decide-. Hay la realización personal: cada hombre es tanto más hombre -persona- cuanto más ha realizado su libertad, cuanto más vive desde la profundidad de sus decisiones axiológicas, cuanto menos es susceptible al influjo de los medios masivos de comunicación.” (2000, p. 136)

\section{b. La libertad de expresión, el derecho y el acceso a la información}

Partiendo del presupuesto de Sanabria en el que afirma que la realización de la libertad es la realización de la persona y que la libertad se ejerce desde las decisiones axiológicas que pueden o no estar mediadas por los medios masivos, hay que hacer notar que para muchos gobiernos legislar en torno a la libertad se ha convertido en un medio de presión más que una forma de velar por el uso correcto de los medios. Si los hombres necesitan satisfacer su necesidad de información para tomar decisiones, autoconfirmarse en el mundo y reproducir con ello un régimen democrático, justo y solidario, la inhibición y el bloqueo de la posibilidad de expresión y acceso a la información, se vuelve un atentado contra la posibilidad de realización de la persona.

Esto implica ampliar el derecho de las personas a saber y beneficiarse con información de mejor calidad para que pueda la sociedad participar en asuntos públicos con mayor conocimiento de causa. Para bien de las personas, la sociedad y la democracia, los medios no deben ser amenazados por los poderes coercitivos en una sociedad; y por otro, que para luchar a favor de la libertad de expresión, los responsables de la comunicación deben esforzarse más por averiguar la veracidad de los hechos. Si los medios han de cumplir su función de ser la conciencia crítica de la sociedad frente a los demás poderes, hay que seguir insistiendo en la evaluación acuciosa de los hechos, la profundización en la actuación como servidores de la sociedad y no de los poderes políticos y el que se garantice el acceso a información fiable, plural y veraz al servicio del bien común. Ante el uso y abuso de las libertades (expresión, prensa, acceso a la información) será importante revisar algunos temas concretos que atañen la responsabilidad y la libertad de los medios como lo son la indecencia, la desregulación, los derechos de autor e Internet.

La Comunicación como Mediación Ética del mundo $\bullet 93$ ante la descentralización de la persona en la acción comunicativa 


\section{c. Equidad y Justicia Social}

Los medios no pueden ser ajenos al desarrollo de los pueblos y mucho menos del de aquellos que buscan en los contenidos de los medios, una participación más amplia de los frutos de la civilización, una valoración más activa de sus cualidades humanas. Si los medios "promueven" la realización humana no se puede dejar de mencionar que hoy día se han desencadenado una serie de atentados contra los valores morales, abusando de los medios para colocarlos al servicio del mercado y no de la persona humana. Está por demás señalar que los medios desempeñan un papel importante en la economía del mercado y es un hecho que la comunicación social sostiene negocios y comercios; pero por encima de ello está el que contribuyan a estimular el progreso y la prosperidad, que promuevan mejoras en la calidad de los bienes y servicios existentes, permitiendo que las personas hagan opciones informadas y que les ayuden a tomar decisiones que les potencien el espíritu cívico y solidario.

\section{d. Indecencia, obscenidad y pornografia}

¿Cuáles son los límites de la transmisión televisiva?, ¿hasta dónde es ético explorar la intimidad, el lenguaje y la corporeidad en Internet para ganar usuarios, "expresarse" y satisfacer "los gustos" de los distintos auditorios? Cada vez son más las quejas que reciben los medios de comunicación por parte de los distintos públicos que se han sentido molestos por la transmisión de programas con contenidos y lenguajes sexuales, indecentes, groseros, vulgares, perversos, vacuos y ofensivos. La obscenidad y la pornografía se han vuelto la fórmula de muchos productores de contenido. Si se suma, la renuncia de los padres a establecer normativas éticas, la falta de responsabilidad de los realizadores, la facilidad de acceso que posibilitan los motores de búsqueda, el anonimato y la gran industria que respalda a la pornografía y la vulgaridad, el problema se agrava a tal grado que se dice que vivimos una cultura de la obscenidad. Basta ver la nota publicada en 1997 por el Washington Post Magazine en el que afirma que el $30 \%$ de los términos de búsqueda están relacionados de forma directa con pornografía y otro $20 \%$ en modo indirecto (Rice, 2000).

\section{e. Desregulación}

¿Existe un punto medio y de equilibrio entre los intereses públicos, privados y comerciales? Cuando se pierde el rumbo de la noción de equidad y justicia social de los medios de comunicación es importante que exista algún mecanismo o institución que vele por el "buen juicio" y "el buen uso" de las difusoras como 
servidoras del interés, conveniencia y necesidades del público garantizando que ante el fenómeno de la desregulación de los medios no se viole, por un lado la libertad de expresión; por otro no se ofenda la dignidad del auditorio. La desregulación de los medios en principio promueve la concentración, conglomeración, el hipercomercialismo, abandono de las normas de la decencia ya que libera al medio de su obligación con el público permitiendo la concentración de los mismos en manos de unos cuantos.

\section{f. Veracidad y honestidad}

¿Hasta dónde se han comprometido los medios para decir la verdad?, ¿cuánto de sus contenidos es una mera parcialización de la realidad? El subjetivismo y el relativismo actual, son los dos grandes pretextos en los que se amparan los malos comunicadores para justificar la imposición de "su verdad". La veracidad y la honestidad informativa deberían ser los principales ejes de acción de los profesionales de los medios; sin embargo, hay medios que insisten en que la verdad no "vende" por ello se han dado a la tarea de manipularla a sus intereses, amplificando la noticia, o reduciendo su impacto para provocar efectos y reacciones según sus intereses. Así, han creado una realidad ajena a la que deberían mostrar. Lo mismo ocurre cuando ignoran temas, distraen la atención o combinan información para imponer su definición de verdad.

\section{g. Privacidad, confidencialidad y problemas personales de intereses}

Uno de los grandes temas a debate con relación a la descentralización de la persona es el derecho a la privacidad. Los reality shows han llevado a la mesa de discusión interrogantes vinculadas con la invasión de la intimidad. Las persecuciones a personajes públicos a través de paparazzis, la exhibición pública de problemas familiares, la publicación de las orientaciones sexuales de las personas, el asalto mediático para explorar gráficamente lo que antes era un secreto matrimonial, son algunos de los tantos puntos que se deben considerar para equilibrar el derecho del público a saber y los intereses de privacidad de las personas. El derecho a la privacidad y la confidencialidad van muy ligadas; ya que por un lado se explota la intimidad de las personas y se busca protegerlos legalmente; y por otro, se exige a los comunicadores que hagan públicas todas sus fuentes y materiales que deben ser de conocimiento público. ¿Existe una media?, ¿qué tipo de información debe mantenerse en secreto mediático?, ¿̨cuáles son los límites de la libertad de expresión?, ¿quién debe regular este aspecto: el gobierno, las instituciones, los medios o la propia persona?, ¿qué implicaciones tiene el

La Comunicación como Mediación Ética del mundo • 95 ante la descentralización de la persona en la acción comunicativa 
que sea sólo el gobierno (con sus respectivos intereses políticos) el que legisle el actuar de los medios, o que quede en manos del sistema de autorregulación del medio (que se gobierna por sus intereses económicos), o que se limite a la práctica ética personal (que también puede estar sesgada ideológicamente)? La mediación ética implica un equilibrio de intereses y un saber jerarquizar valores en función de las consecuencias de los actos. La gran interrogante es ¿̨cuántos de los comunicadores están preparados moralmente para sopesar esta realidad y en manos de quién debe recaer esta formación?

LA MEDIACIÓN ÉTICA COMO ALTERNATIVA

Para resolver gran parte de estos conflictos de contenido e interés y garantizar un manejo equilibrado de los medios, se desarrolló en 1947 un informe titulado "Teoría de la responsabilidad social de la prensa" a cargo de La Comisión Hutchins sobre la Libertad de Prensa. Esta teoría normativa proponía una guía práctica para operar idealmente los medios en un sistema dado de valores. Además, afirma que los medios deben estar exentos de controles gubernamentales pero a cambio deben servir al pueblo. Algunas de sus premisas básicas han son: 1) Los medios deben aceptar y cumplir ciertas obligaciones con la sociedad; 2) Para cumplir estas obligaciones, los medios pueden fijar normas elevadas de profesionalismo, veracidad, fidelidad y objetividad; 3) Los medios deben regularse ellos mismos en el marco de la ley; 4) Los medios no deben difundir material que incite a la delincuencia, violencia o trastornos civiles o que ofenda a grupos minoritarios; 5) Los medios en conjunto deben ser plurales, deben reflejar la diversidad de la cultura en la que operan y deben dar cabida a diversos puntos de vista y al derecho de réplica; 6) El público tiene derecho a esperar un desempeño elevado y la intervención oficial se justifica en aras del bien público; 7) Los profesionales de los medios deben ser responsables ante la sociedad así como ante sus patrones y el mercado. Con estos principios en mente se busca involucrar a todos los sectores (gobierno, medios, comunicadores y auditorios) para hacerlos conscientes de su responsabilidad.

La teoría de la Responsabilidad Social de los Medios ofrece esquemas interesantes, tanto formales como informales para controlar a la industria mediática y verificar que los profesionales cumplan responsablemente con su deber. Pero, ¿se puede ir más allá de las leyes y los reglamentos? La ética, en su propia ontología nos ofrece la gran solución; puesto que consiste en reglas y principios que guían la conducta y ayudan a decidir responsablemente ante ciertas situaciones. Es la

96 • Jorge Alberto Hidalgo Toledo, José Antonio Forzán Gómez 
misma ética la que ayuda a discernir racionalmente equilibrando los controles externos formales (leyes, reglamentos, códigos de ética) y los internos (tanto los de la industria como los personales). La aplicación de la ética en los medios permitiría devolver la centralidad de la persona en los medios de comunicación. Si cada comunicador partiera de la ética para definir su posición ante cada problema que cubre, terminaría por un lado, profundizando en el conocimiento de sí mismo y, en segundo lugar, definiendo hasta dónde puede garantizar que lo comunicado ayude a la construcción de la identidad del otro.

\section{a. La ética en los medios}

Como se ha puntualizado a lo largo de este texto, los medios cumplen una misión trascendental que es unir a los hombres. Si este objetivo se realiza partiendo de la ética, servirá para difundir la verdad, hacer más conscientes a los individuos de la dignidad de la persona, más responsables, más tolerantes y abiertos a las necesidades de los demás, para con ello participar en actividades que favorezcan el bien común. La mediación ética se hace presente cuando la intención (de quien envía el mensaje), promueve o no valores (el mensaje mismo), para que alguien realice o no actos morales (interpretación, respuesta y retroalimentación).

\section{b. Beneficios de la práctica ética}

La apuesta por la mediación ética puede traer beneficios en múltiples planos. Su práctica e impacto puede llevar a la realización de la persona y a que ésta alcance la plenitud.

- En lo económico. Los medios impulsan los mercados y sostienen muchos negocios gracias a la publicidad. También estimulan el empleo y promueven mejoras en la calidad de los bienes y servicios. En la medida que fomenten una competencia sana y responsable podrían contribuir en la justicia social.

- En lo político. La transmisión de mensajes apegados a la verdad y sin pretensiones ideológicas manipuladoras, podrían beneficiar a la sociedad para que las personas participen más en los procesos políticos. Los medios podrían llamar la atención en casos de incompetencia, corrupción, abuso de confianza o promover la competencia, el espíritu cívico y el cumplimiento del deber.

- En lo cultural y educativo. Los medios podrían llevar a las personas a entender las prácticas culturales y las tradiciones de los demás pueblos; así como a valorar el patrimonio cultural y preservarlo.

La Comunicación como Mediación Ética del mundo $\bullet 97$ ante la descentralización de la persona en la acción comunicativa 
- En lo educativo. Los medios ofrecen herramientas e instrumentos complementarios a la formación de niños, adolescentes, padres de familia y ancianos. Con su penetración, la educación puede llegar a los sectores más marginados y ofrecerles una visión esperanzadora del mundo.

- En lo personal. Los medios pueden enriquecer la experiencia vital al transmitir mensajes, noticias, ideas y acontecimientos positivos que inspiren, alienten y lleven a las personas a participar en hechos trascendentales. Los contenidos deben hacer a las personas conscientes de la dimensión ética y moral de la información de lo contrario, no aportará sentido alguno a su existencia.

\section{c. Faltas a la práctica ética}

Los medios, así como pueden ser empleados para beneficio de la sociedad, también pueden entorpecer su desarrollo dañando la integridad de las personas, marginándolas, manipulando o pervirtiendo sus valores. Siguiendo el esquema de interrelación que existe entre la sociedad, la cultura y la comunicación, se mencionan a continuación dónde se pueden remarcar la descentralidad de la persona:

- En lo económico. Hay empresarios que emplean los medios apoyar sistemas económicos que promueven la avaricia y la ambición. Al no existir órganos internacionales de control que guíen y orienten la participación de los medios en el proceso de globalización, se están desaprovechando las oportunidades de llevar mayor bienestar a las comunidades más explotadas y marginadas.

- En lo politico. Es común ver que se emplean los medios para hacer proselitismo o para manipular la opinión pública. Hay incluso quienes aplican técnicas publicitarias o de relaciones públicas para explotar a ciertos grupos o violar los derechos humanos. Otro de los errores comunes es el uso de los medios para difundir una visión utilitaria o de gran relativismo ético.

- En lo cultural. Basta analizar la superficialidad con que son tratados ciertos temas trascendentales y el mal gusto que impera en la construcción de contenidos. Esto es producto de la estrechez de miras, la uniformidad, la vulgaridad y la degradación que se hace de la persona y sus tradiciones.

- En lo educativo. La auténtica educación está para ampliar el conocimiento y potenciar las capacidades de las personas, no para oprimirlas o ponerlas al servicio de alguna ideología.

- En lo personal. Algunos medios han excluido los temas espirituales y los valores religiosos para promover por un lado el racionalismo y el escepti-

98 • Jorge Alberto Hidalgo Toledo, José Antonio Forzán Gómez 
cismo; otros se van al extremo y presentan los mensajes religiosos con un estilo emotivo y manipulador (para competir en el mercado) que fomenta el fanatismo, los sincretismos, la exclusividad, el desprecio y hostilidad hacia los demás minimizando el verdadero sentido religioso.

\section{d. Códigos de ética y autorregulación}

Para apoyar a los profesionales de los medios en sus razonamientos éticos, se han creado infinidad de códigos formales y normas de conducta. Muchos de ellos se quedan en el plano prescriptivo y se limitan a decir a los comunicadores lo que deben o no hacer. Para muchos, los códigos sólo ofrecen una lista de lugares comunes sin valor legal que restringen su libertad de expresión, mientras que para otros se han vuelto el sentido de su misión comunicativa. En principio los códigos deberían ofrecer una fuente de información para emitir juicios morales más que protecciones egoístas para la industria que en ocasiones atenta contra la sociedad.

Existen también los códigos profesionales de la industria. Estos son políticas institucionales de comportamiento que incluyen tanto las operativas, las editoriales, las administrativas y las de evaluación -que son modos de examinar la opinión pública. Estos mecanismos de "ética normativa" son una forma de autorregulación que tiene por objeto el evitar el exceso de intervención y volver operativas las normas éticas o deontológicas que se imponen a sí mismos los comunicadores. Las limitaciones de estos códigos son que: muchas de sus normas son abstractas y ambiguas; los profesionales son reacios a señalar o censurar a sus colegas; al formar parte de una organización los comunicadores tienen poco control sobre su trabajo.

La participación de los distintos auditorios se vuelve fundamental para la fiscalización de los medios y el ejercicio de la autorregulación. De ahí que a la par del desarrollo de códigos éticos, algunos medios formaran consejos de ética y grupos observadores de su acción. Desgraciadamente, en la parte operativa encontramos que muchos son los medios que han recurrido a la práctica de la autorregulación para evitar la imposición legal del gobierno y evitar causar la menor conmoción. Las funciones elementales de la autorregulación según Albarrán de Alba son: "1) Establecer las normas éticas a que se deben sujetar voluntariamente tanto los empresarios de la información como los periodistas. 2) Contribuir a crear las condiciones de normalidad -tanto en lo laboral como en lo profesional y lo social- para el cumplimiento de éstas. 3) Brindar elementos de juicio crítico al público sobre el desempeño de los propios medios. 4)

La Comunicación como Mediación Ética del mundo • 99 ante la descentralización de la persona en la acción comunicativa 
Socializar los procesos de toma de decisión en los medios y el conocimiento que deriva del diálogo ético de los periodistas" (2004, p. 43).

Idealmente la autorregulación debería ser un instrumento de defensa de las libertades de expresión e información siempre que se encuentren amenazadas. En el caso de la ética de los medios, no está restringida al ámbito de la conciencia individual de cada comunicador o de los editores o productores. Esta debe responder a una construcción colectiva que no pierda de vista en ningún momento a la sociedad. La ética debe servir al comunicador como herramienta para hacer bien su trabajo y como punto de partida y finalidad misma de la profesión. Aquí subyace la discusión actual sobre la ética en los medios de comunicación: ¿cómo hacerla operativa si los códigos y las bases éticas que se están implementando no consideran todos los aspectos de la dignidad de la persona, la misión y responsabilidad del medio, así como el bien común? Quizá, algunas de las tantas soluciones a esta interrogante están en: el cambio de mentalidad de los comunicadores; en la formación ética de cada uno de los actores morales (tanto empresarios de los medios, comunicadores y receptores); el que exista un marco legal estructurado que regule las responsabilidades de todos y de cada uno; en una mayor participación y diálogo de la sociedad civil en la industria de los medios para garantizar que los contenidos respondan a sus legítimos intereses; que se contemple que los medios son vehículos que garanticen la solidaridad, la justicia, el diálogo, la paz y el bien común.

Dos PROPUESTAS DE MEDIACIÓN ÉTICA APLICADA

La mediación ética no se puede quedar sólo en quienes emiten los mensajes, también es importante fomentar una educación mediática para que todos aprendan a valorar y usar los instrumentos de comunicación. Cada persona es responsable de la formación de su conciencia; si todos los mensajes son recibidos pasivamente sin espíritu crítico las personas fácilmente pueden ser víctimas de intereses amorales. Al aplicar la ética, cada persona pasa a ser un agente moral, un mediador ético de la realidad. De ahí la importancia de una alfabetización ética crítica y activa. No basta exigirle a los medios responsabilidad, sensibilidad, verdad y respeto a la vida humana; también los espectadores deben ser coherente con esa exigencia. Así, como los medios hoy día empiezan a crear sus códigos de ética para regular sus acciones e implementan la autorregulación para normarse, cada persona debe tener claro cuál es su código de ética para acceder a los contenidos y de qué manera se autorregulará. En la medida que

ıоo • Jorge Alberto Hidalgo Toledo, José Antonio Forzán Gómez 
cada persona practique una recepción crítica, su convivencia con los medios será más plena, rica y llena de sentido.

\section{a. La Semioética o alfabetización ética del lenguaje}

La dimensión ética del lenguaje empieza cuando entra en escena el otro. Si el contacto entre el yo y el tú se establece a través del lenguaje, y la mirada al otro regula mi accionar social, es fundamental concebir una ética de la significación, es decir, dar espacio a la semioética en la alfabetización de toda persona. $\mathrm{Al}$ entrar en contacto con el otro, nos damos cuenta de que debe haber una regulación de la relación con el otro. Una normatividad que se establezca desde la instrucción en el lenguaje que enseñe a las personas a codificar y decodificar los aspectos fundamentales de todo mensaje. Esta instrucción de formar a las personas a la construcción de relaciones expresivas, libres y encausadas por un sistema moral. La alfabetización semioética se distinguiría de la construcción de códigos para centrar su preocupación activa en el lenguaje, en la ética del discurso escrito, visual o sonoro.

Una alfabetización semioética permitiría a la persona identificar ilusiones ideológicas, lo impuro de la lengua, los eticismos, las falsas conciencias, las idolatrías históricas, la pobreza léxica, la corrupción del mensaje, los temores infundidos, las insinuaciones, la manipulación, las agresiones y las sintaxis elementales.

Así, quien se forme en el ethos de la significación podría leer y diseñar productos comunicativos que tomen en cuenta al otro en su dignidad de persona humana.

\section{b. Infoética o la alfabetización de la auto y corregulación}

Dado que la comunicación se inscribe en la cuestión antropológica, la infoética debe constituirse como una alfabetización que permita a la persona y a los comunicadores preservar la defensa de la dignidad humana. Alcanzar una mediación ética integral a la medida de la dignidad de la persona y del bien común es responsabilidad de todos. Por ello, una alfabetización infoética daría las herramientas a los profesionales para la elaboración y aplicación de códigos normativos, de auto y corregulación. A los usuarios les formaría la conciencia para discernir, seleccionar, leer, ver, escuchar, escribir y cantar prudentemente en los medios. Les permitiría pasar de ser receptores pasivos a activos y portadores de sentido. Una instrucción infoética debe conjuntar la estética con la excelencia moral, con el ejercicio de la libertad, con la formación de criterios

La Comunicación como Mediación Ética del mundo • Iо I ante la descentralización de la persona en la acción comunicativa 
de buen gusto apoyados en el análisis y la crítica que permiten una interacción positiva con los demás.

Contar con esta alfabetización permitiría que cada persona asuma su condición de prosumer (productor-consumidor) participando crítica y activamente como productor cultural, como productor de sentido para la propia vida y la de los otros.

\section{REFERENCIAS}

Albarrán de Alba, G. (2004). "Autorregulación periodística. Una aproximación a sus elementos medulares". En Revista Mexicana de Comunicación, (N. 84), Año Dieciséis, noviembre 2003-enero 2004. México: Fundación Manuel Buendía, A. C.

Barbero, J. M (1987). De los medios a las mediaciones. México: Gustavo Gili.

Barthes, R. (2004). Lo neutro. México: Siglo xxi.

Barthes, R. (2001). La Torre Eiffel. Barcelona: Paidós.

Barthes, R. (2000). El placer del texto; Lección inaugural. México: Siglo xxi.

Baudrillard, J. (1996). El crimen perfecto. Barcelona: Anagrama.

Bennett, W. J. (2001). El libro de las virtudes para jóvenes. Bilbao: Javier Vergara Ed.

Cassirer, E. (1985). Filosofía de las formas simbólicas. México: FCE

Eco, U. (2000). Cinco escritos morales. España: Lumen.

Fromm, E. (1986). Ética y psicoanálisis. México: Fondo de Cultura Económica.

Gubern, R. (2000). El eros electrónico. México: Taurus.

Gubern, R. (1999). Del bisonte a la realidad virtual. Barcelona: Anagrama.

Heidegger, M. (1987). De camino al habla. Barcelona: Serval-Guitard.

Baran, S. y Hidalgo Toledo, J. A. (2005). Comunicación masiva en Hispanoamérica. Cultura y literatura mediática. México: McGraw Hill.

Hidalgo Toledo, J. A. (2005). "El coraje ético más allá de la moda de la responsabilidad social”. En Comunicación estratégica en las organizaciones. Rebeil Corrella, M.

A. (Coord.). México: Trillas.

Lipovetsky, G. (1998). El crepuisculo del deber. Barcelona: Anagrama.

López Quintás, A. (1968). Pensadores cristianos contemporáneos. Madrid: BAC.

Márquez López, F. (2003). El Nuevo Orden Mundial de la Comunicación en la era de la sociedad de la información. FCPyS-UNAM, México.

Moles, A. (Ed.) (1975). La comunicación y los mass media. Bilbao: Ediciones mensajero.

Rice Huges, D. (2000). Niños en Internet México: Oxford University Press.

Sanabria, J. R (2000). Filosofía del hombre. México: Porrúa.

Sartre, J. P. (2000). El ser y la nada. Buenos Aires: Losada.

Serrano, J. (1970). La soledad humana. Salamanca: Sígueme.

Zubiri, X. (1987). Naturaleza, Historia, Dios. Madrid: Alianza Editorial.

I02 • Jorge Alberto Hidalgo Toledo, José Antonio Forzán Gómez 